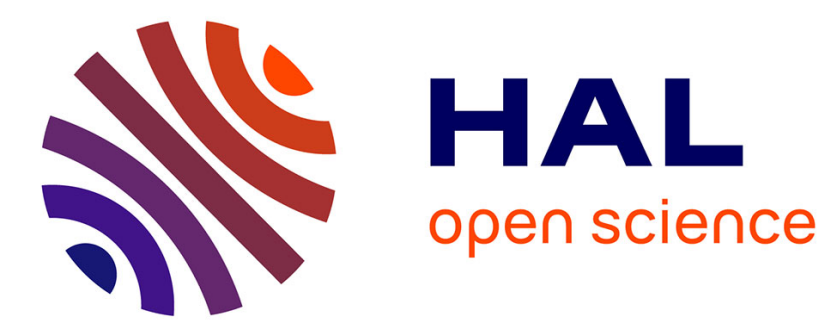

\title{
Response of water-exchange capacity to human interventions in Jiaozhou Bay, China
}

\author{
Yuan Yuan, Isabel Jalón-Rojas, Xiao Hua Wang
}

\section{To cite this version:}

Yuan Yuan, Isabel Jalón-Rojas, Xiao Hua Wang. Response of water-exchange capacity to human interventions in Jiaozhou Bay, China. Estuarine, Coastal and Shelf Science, 2021, 249, pp.107088. 10.1016/j.ecss.2020.107088 . hal-03438924

\section{HAL Id: hal-03438924 \\ https://hal.science/hal-03438924}

Submitted on 22 Nov 2021

HAL is a multi-disciplinary open access archive for the deposit and dissemination of scientific research documents, whether they are published or not. The documents may come from teaching and research institutions in France or abroad, or from public or private research centers.
L'archive ouverte pluridisciplinaire HAL, est destinée au dépôt et à la diffusion de documents scientifiques de niveau recherche, publiés ou non, émanant des établissements d'enseignement et de recherche français ou étrangers, des laboratoires publics ou privés. 


\title{
Response of water-exchange capacity to human interventions in Jiaozhou Bay, China
}

\author{
Yuan Yuan ${ }^{1 *}$, Isabel Jalón-Rojas ${ }^{1,2}$, Xiao Hua Wang ${ }^{1}$ \\ ${ }^{1}$ The Sino-Australian Research Consortium for Coastal Management, School of Science, The \\ University of New South Wales, Canberra, ACT 2600, Australia \\ ${ }^{2}$ UMR5805 EPOC, CNRS, OASU, Univ. Bordeaux, Pessac, France \\ *Correspondence: yuan.yuan1@ @ student.adfa.edu.au Tel: +61416341127
}

\begin{abstract}
Intensive anthropogenic activities, land reclamation, a cross-bay bridge construction, and the correction of Red Island have significantly changed the topography of Jiaozhou Bay (JZB) in northern China over the last decades. To quantify the effects of these modifications on the water-exchange capacity of the bay, the Finite Volume Community Ocean Model was used to calculate basin, regional and local residence time (RT) in the years 1935, 1966, 1986, 2000, 2008, and 2013, covering the periods of significant land reclamation. The bridge construction and a government plan to restore Red Island were also included in additional modelling scenarios. The regional RT increased significantly between 1935 and 1986, by $77 \%$ in the northeast, $40 \%$ in the west and $56 \%$ in the north-bridge regions, concurrent with the largest land reclamation. The regional RT continued to increase from 1986 to 2000 in the northeast and north-bridge regions but decreased slightly from 2000. These patterns can be explained by the general decreasing trend of the tidal prism from 1935 to 2000 , up to $66 \%$ in the northeast region. A significant decrease in residual currents from 1935 to 1966 probably also contributed to explain this trend. The bridge construction had only a limited effect on regional RT. The restoration of Red Island would have reduced the regional RT in the northeast region from 83
\end{abstract}


to 60 days. The simulation of tracer transport, and therefore calculation of local RT, was found to be sensitive to the scheme used to formulate the horizontal diffusion coefficient, which should be taking into account when comparing results from different model configurations.

Key words: Jiaozhou Bay; water-exchange capacity; residence time; land reclamation; bridge construction; horizontal diffusion coefficient.

\section{Introduction}

Coastal areas are subject to continuous environmental pressure from human activities, and can easily become eutrophic ecosystems because of the increased discharge of nutrients and contaminants (Diaz and Rosenberg, 2008). Coastal systems purge themselves of contaminants by complex natural processes involving hydrological, chemical and biological mechanisms (Ostroumov, 2006). The water exchange between a coastal sea and the adjacent open ocean is key to describing its self-purification characteristics.

Transport timescale is a key parameter in assessing water-exchange capacity (Takeoka, 1984), which can be expressed in terms of residence time (RT), flushing time, turn-over time, transit time or age (Zimmerman, 1976). RT, the most widely used timescale, is the time spent by a water parcel in a predefined region (Kenov et al., 2012; Takeoka, 1984). Transport timescales have been largely estimated using numerical models for many coastal areas around the world, particularly in coastal embayments (Banas and Hickey, 2005; Lin et al., 2017; Safak et al., 2015; Sun et al., 2018; Xing et al., 2013). In recent years, particular attention has been paid to the effect of human interventions (e.g., land reclamation, dredging and construction of canals and levees) on flushing efficiency. Several studies have reported that more (less) freshwater input resulted in shorter (longer) times to renew the water in a bay, for example in Xiaohai 
Lagoon in China (Gong et al., 2008), Tokyo Bay in Japan (Okada et al., 2011) and Cartagena Bay in Colombia (Tosic et al., 2019).

Land reclamation is one of the most widespread interventions worldwide (Cheng et al., 2020; Cui et al., 2016), acquiring land from the sea for agriculture, industry, etc. It can cause either an enhancement or a deterioration in the water-exchange capacity, depending on the local hydrodynamics. For example, an increase in RT following land reclamation was reported in Yueqing Bay in China (Ying et al., 2018), Xiaohai Lagoon in China (Gong et al., 2008), and Tokyo Bay in Japan (Okada et al., 2011), while Deep Bay in China (Yang and Chui, 2017) experienced a decrease. Simultaneous human interventions can have a combined effect on water renewal in a bay. For example, the water-exchange capacity in Xiaohai Lagoon was degraded by both land reclamation and a reduction in freshwater runoff (Gong et al., 2008). Another example is the decrease in the flushing capacity of Venice Lagoon in Italy from 1927 to 2012 due to the simultaneous effects of land reclamation, dredging and mobile-barrier construction (Ferrarin et al., 2013). Understanding the evolution of water exchange in humanimpacted bays may require specific modelling of individual bays (e.g., Jia et al., 2018; Zarzuelo et al., 2015). Moreover, knowledge on the effect of coastal infrastructure such as bridges on water renewal is still limited.

Jiaozhou Bay (JZB) is a shallow semi-enclosed bay, located on the coast of the Yellow Sea (eastern China, Fig. 1a). This bay has been subject to intensified interventions, including land reclamation and construction of a cross-shore bridge, and so is a good example for evaluating anthropogenic impacts. As in similar bays, the water-exchange capacity varies spatially, generally decreasing from the entrance to the head of the bay. Several studies of JZB have identified a lower water-exchange capacity in the west (Liu et al., 2004; Lv et al., 2010; Wang et al., 2009; Zhao et al., 2002) and northeast (Lv et al., 2010) regions. However, these studies used different methodologies and definitions of the transport timescales and, consequently, did 
not reach quantitive agreement. The basin water exchange timescale for JZB was estimated in the range 5 to 80 days (Chen et al., 2019; Liu et al., 2004; Lv et al., 2010; Shi et al., 2011; Wang et al., 2009; Wu et al., 1992; Yang et al., 2013; Zhao et al., 2002).
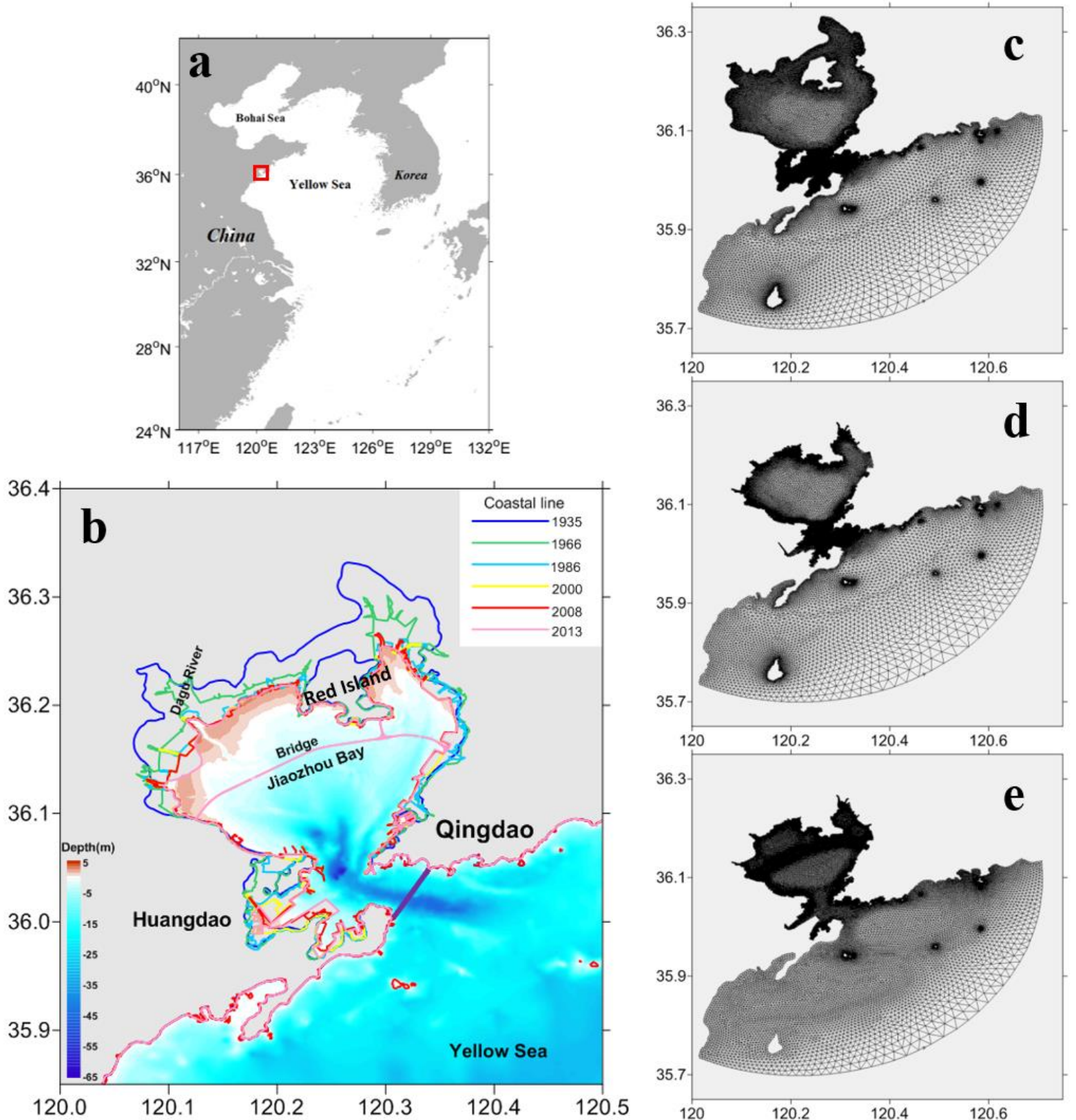

Fig. 1. (a) Location of JZB on the Yellow Sea coast. (b) Bathymetry map of JZB showing the coastline evolution from 1935 to 2013 (coloured lines), with the purple line at the bay entrance defining the boundary of the inner bay. JZB model mesh and grid distributions for (c) 1935, (d) 2008, (e) 2013. 
According to Shi et al. (2011), the water-exchange capacity of JZB decreased from 1966 to 2008 due to land reclamation. However, the largest reclamation took place between 1935 and 1966, leading to significant hydrodynamic changes (Gao et al., 2014). The impact of these first large-scale interventions on water renewal remains unknown, but this knowledge is essential in understanding the whole evolution of the bay from its pristine state.

There are also contrasting findings in the literature regarding the effect of the bridge construction on the JZB hydrodynamics. The simulation by Li et al. (2014) showed a large impact of the bridge on tidal characteristics; Yuan et al. (2019b) found only a moderate effect, and suggested that the use of different mesh sizes between the Li et al. (2014) scenarios may have caused unexpected discrepancies in their numerical calculations. Therefore, the impact of the bridge on the JZB water-exchange capacity is still not clear. The future management and

planning of the bay (e.g., for coastal restoration and coastal infrastructure) need a comprehensive understanding of the whole historical evolution of water-exchange capacity, as well as an evaluation of possible future scenarios.

The aim of this paper is to evaluate the impact of three types of human activities on the waterexchange capacity in JZB: land reclamation from 1935 to 2013; the bridge construction in 2013 scenario; and the Red Island reclamation in 1935 and its hypothetical restoration in 2013. The water-exchange capacity of the bay is quantified at both basin- and region- scale for the different scenarios. A sensitivity test establishes how the model response varies with changes in the horizontal diffusion coefficient. This is the first study to evaluate the joint effects of all the large engineering interventions in JZB, including a restoration scenario.

\section{Study area}

Located on the northeast coast of China, JZB is $33 \mathrm{~km}$ long and $28 \mathrm{~km}$ wide (Liu, 1992). The averaged water depth is $7 \mathrm{~m}$, with a maximum of $64 \mathrm{~m}$ in the middle channel (Fig. 1b). The 
bay hydrodynamics is dominated by semidiurnal tidal currents (Wu et al., 1992). Current velocities are higher than $0.15 \mathrm{~m} / \mathrm{s}$, and can reach $1.7 \mathrm{~m} / \mathrm{s}$ at the entrance to the bay (Wu et al., 1992). Weak and strong clockwise residual currents occur in the shallow and southern regions of the bay, respectively (Chen et al., 1999). The annual runoff from the rivers discharging into JZB experienced a considerable decrease trend since recent decades, from approximately $11 \times 10^{8} \mathrm{~m}^{3}$ in the $1960 \mathrm{~s}$ to $3 \times 10^{8} \mathrm{~m}^{3}$ in 2008 (Sheng et al., 2014), and then to $2.2 \times 10^{8} \mathrm{~m}^{3}$ in 2015 (Sun et al., 2016). The effect of river discharge on residual currents is insignificant, while the southeasterly wind (in spring and summer) tends to change the typical clockwise circulation in the shallow regions to a northwestward water transport near the surface (Chen et al., 1999). JZB has been largely impacted by human interventions from the surrounded city, Qingdao, which has an increasingly prosperous economy. Over the last few decades, the coastline of JZB has been changed significantly by the land reclamation (Fig. 1b), resulting in a $40 \%$ decline in its area (Chen and Chen, 2012). A 27km-long bridge (called the JZB Bridge here) was built across the bay from 2007 to 2011 (Yuan et al., 2019a). Red Island (Fig. 1b) was connected to the mainland in 1935, but the Qingdao government currently plans to restore it as an island.

As a consequence of urbanization, a significant increase in pollutants over last 30 years (Liang et al., 2015) has led to water-quality deterioration (Qiao et al., 2019). From 1990 to 2012, the amount of wastewater flowing into the bay from the city grew from 2.1 to 5.6 tonnes per person per year (Liang et al., 2015). Terrigenous dissolved inorganic nitrogen is the dominant pollutant, with its annual discharge rising by 10 times from the 1980s to the 2000s (Dong et al., 2010; Qian et al., 2009; Wang and Li, 2006). Algal blooms, a consequence of the increase in nutrients in the water, can induce oxygen depletion (Smith, 2003). The evolution on the water-exchange capacity over the last decades could have influenced these water-quality issues.

\section{Methods}




\subsection{Model description}

The Finite Volume Community Ocean Model (FVCOM, Chen et al. (2003)) was applied to different historical scenarios to simulate the hydrodynamics and calculate the residence time (RT) in JZB. We used the model configurations for 1935, 1966, 1986, 2000, and 2008 validated by Gao et al. (2014), and the model configuration for 2013 validated by Yuan et al. (2019b). FVCOM is a free-surface, 3D primitive-equation coastal ocean circulation model. It uses flexible unstructured grids, which can be readily adapted to complicated topographies at small scales, such as in JZB. The model was applied to nine scenarios in three categories:

a) land reclamation: 1935, 1966, 1986, 2000, 2008, and 2013 without the bridge;

b) bridge construction (using the 2013 model);

c) two Red Island scenarios: Red Island connected to the mainland in 1935; Red Island (hypothetically) detached from the mainland in 2013.

The two scenarios in (c) were designed to quantify the effects on the water-exchange capacity of the reclamation of Red Island in 1935 and its planned restoration (using the 2013 model).

The grids for JZB between 1935 and 2008 had a minimum cell size of $50 \mathrm{~m}$ and a maximum of $2500 \mathrm{~m}$ (see the grids for 1935 and 2008 as examples in Figs. 1c and d, respectively). In the case of the bridge construction in 2013, the grid resolution near the JZB Bridge was increased to determine the effects of the 864 bridge piers on the hydrodynamic environment (Fig. 1e). Each pier occupied a whole cell (resolution of $7 \mathrm{~m}$ ), which was identified as a no-water area. A secondary grid of the same resolution but with no piers was developed by Yuan et al. (2019b), and was used here to simulate the 2013 scenario without the bridge. The grid resolution for the 2013 scenarios was much finer than for the other scenarios; this could affect the horizontal diffusion coefficient $A_{\mathrm{h}}$ from the Smagroinsky scheme, and therefore the resulting RT. 
Therefore, we selected a constant $A_{\mathrm{h}}$ (more information in Section 3.4.2). A detailed analysis of the sensitivity of the RT to the formulation and values of this parameter is also given in Section 3.4.2. More details on the model settings are given in Gao et al. (2014) and Yuan et al. (2019b).

Regarding validation of the hydrodynamic model, there was a general good agreement between simulated and observed tidal variables, such as tidal elevation. The differences between the observed and simulated amplitudes and phases of the tidal harmonics were less than $5 \mathrm{~cm}$ and $5^{\circ}$, respectively (Gao et al., 2014; Yuan et al., 2019b). Gao et al. (2014) used tidal ellipse to compare observed and simulated tidal currents; the differences in the $\mathrm{M}_{2}$ tide semi-major, semiminor axes, inclinations, and phases were $3.7 \mathrm{~cm} / \mathrm{s}, 1.1 \mathrm{~cm} / \mathrm{s}, 6.0^{\circ}$, and $7.7^{\circ}$, respectively. Yuan et al. (2019b) compared 66 time series of observed and simulated tidal-current directions and velocities; $85 \%$ of the $R^{2}$ values were higher than 0.5 .

An Eulerian tracer-tracking module was coupled to the FVCOM hydrodynamic model to simulate tracer transport for each scenario. The formulation for the tracer movement is (Chen et al., 2013):

$$
\frac{\partial D C}{\partial t}+\frac{\partial D u C}{\partial x}+\frac{\partial D v C}{\partial y}+\frac{\partial \omega C}{\partial \sigma}=\frac{1}{D} \frac{\partial}{\partial \sigma}\left(K_{h} \frac{\partial C}{\partial \sigma}\right)+\frac{\partial}{\partial x}\left(A_{h} D \frac{\partial C}{\partial x}\right)+\frac{\partial}{\partial y}\left(A_{h} D \frac{\partial C}{\partial y}\right)
$$

where $C$ is the concentration of the tracer, $D$ the total water depth, and $u, v$, and $\omega$ are the $x, y$, and $\sigma$ components of the water velocity, respectively. $K_{\mathrm{h}}$ is the vertical eddy diffusion coefficient and $A_{\mathrm{h}}$, the horizontal eddy diffusion coefficient, is taken here to be a constant 3 $\mathrm{m}^{2} / \mathrm{s}$ (Section 3.4.2).

The model was forced at the open boundary by eight major tidal constituents $\left(\mathrm{M}_{2}, \mathrm{~S}_{2}, \mathrm{~K}_{1}, \mathrm{O}_{1}\right.$, $\mathrm{N}_{2}, \mathrm{P}_{1}, \mathrm{~K}_{2}$, and $\left.\mathrm{Q}_{2}\right)$ and three shallow-water constituents $\left(\mathrm{M}_{4}, \mathrm{MS}_{4}\right.$, and $\left.\mathrm{MN}_{4}\right)$. In order to highlight the anthropogenic effects on the water-exchange capacity, the same forcing was 
applied to all scenarios. Less-significant forcings such as river discharge and wind were ignored, as explained by Gao et al. (2014). After 8 days of spin-up time for numerical stability, the model simulation covered a period of 5 months from $1^{\text {st }}$ July to $1^{\text {st }}$ December in each scenario. The model started in summer in order to incorporate the period of algae blooms, which cause oxygen depletion and affect aquatic life in JZB, which will allow us to discuss the implications of this work on the water-quality issues. A simulation duration of 5 months is long enough to capture the flushing properties in JZB according to previous work (Chen et al., 2019; Liu et al., 2004; Shi et al., 2011).

\subsection{Residence-time calculation}

We applied an Eulerian definition of RT, which has been widely used in shallow coastal systems such as the Gulf of Kachchh (Patgaonkar et al., 2012), Tampa Bay (Zhu et al., 2015), and Jervis Bay (Sun et al., 2018). A passive tracer with concentration set to 1 was released at each grid point in the inner bay (purple line in Fig. 1b) on $1^{\text {st }}$ July (time $t_{0}$ ). No further tracer was added after $t_{0}$, and the volume $V_{i}$ of each grid cell in the bay remained constant over time. The concentration $C_{i}$ of tracer at each grid point evolved with time $(t)$ as the bay exchanged water with the open sea; the relative tracer mass (RTM) is given by Sun et al. (2018):

$$
\operatorname{RTM}(t)=\frac{\sum_{i=1}^{n} C_{i}(t) V_{i}(t)}{\sum_{i=1}^{n} C_{i}\left(t_{0}\right) V_{i}\left(t_{0}\right)}
$$

where the subscript $i$ labels the grid points in the inner bay. Here the $C_{i}\left(t_{0}\right)=1$, the initial conditions, so the denominator of Eq. (2) is just the total volume. The basin RT was taken to be the time at which the total tracer mass in the inner bay first fell below $\mathrm{e}^{-1}(37 \%)$. The local $\mathrm{RT}$, the RT at a grid point, was taken to be the time at which the depth-averaged tracer concentration at that grid point fell below $\mathrm{e}^{-1}$. 
We also calculated the regionally averaged RT for three regions of JZB: the west, the northeast, and the north-bridge regions (Fig. 7d); this was used as a metric to better understand the evolution of the local RT. We selected the west and northeast regions as previous studies suggested that these regions have a lower water-exchange capacity (review in Section 1); the north-bridge region was selected to determine the bridge effects. To avoid errors in the calculation of these regional RT because of the differences in grid resolution for the different scenarios, we used the following averaging method: (1) calculate the RT at the grid points in the target region; (2) interpolate these local RT to a uniform grid common to all scenarios; (3) use the average of the interpolated local RT as the regionally averaged RT.

\subsection{Tidal-prism calculation}

The tidal prism is the difference in the volume of water in a bay between high tide and low tide (Ketchum and Rawn, 1951) or the volume of water imported by the tide. According to this definition, the tidal prism $P_{1}$ during one tidal cycle is given by:

$$
P_{1}=\left[\sum_{i=1}^{n} D_{i}(t) \cdot S_{i}(t)\right] \mid \begin{aligned}
& T_{h} \\
& T_{l}
\end{aligned}
$$

where the subscript $i$ again labels grid points in the inner bay, $D_{i}$ is the total depth at grid point $i$ and $S_{i}$ the area of the corresponding grid cell. $T_{\mathrm{h}}$ is the time at which high tide occurs, $T_{1}$ the following low tide. The mean tidal prism $P$ is then the average of all the tidal cycles $P_{1}$ during the model running time.

\subsection{Comparison of different grid sizes}

We checked whether the differences in grid resolution between the 2013 and the 1935-2008 scenarios caused any discrepancies in the numerical calculations of the RT. For this purpose, we compared the basin and local RT calculated with two different grids for the 2013 scenario without the bridge: (a) the finer grid used in Yuan et al. (2019b) and in this study (Grid F); and 
(b) a coarser grid generated by modifying the 2008 grid (Grid C). The differences between the original 2008 grid and Grid C were only along the coastline, with no modification of the grid patterns. The coarser Grid C contained 26,037 points, compared with 85,319 points in Grid F.

\subsection{Schemes for sensitivity analysis of horizontal diffusion coefficient}

There are a variety of methods to estimate the horizontal diffusion coefficient $A_{\mathrm{h}}$ (Gordon and Stern, 1982; Grell et al., 1994; Hancock et al., 2006; Smagorinsky, 1963), which is an important parameter in the numerical simulation of passive tracer transport and flushing efficiency in coastal areas. $A_{\mathrm{h}}$ can be assumed to be constant or to vary in space and time. The Smagorinsky scheme (Smagorinsky, 1963) is the most widely used formulation in this latter case (Berntsen, 2002); $A_{\mathrm{h}}$ in this scheme depends on the area of the grid cells, and is given as:

$$
A_{h}=\frac{0.5 C_{0} \Omega}{P_{r}} \sqrt{\left(\frac{\partial u}{\partial x}\right)^{2}+0.5\left(\frac{\partial v}{\partial x}+\frac{\partial u}{\partial y}\right)^{2}+\left(\frac{\partial v}{\partial y}\right)^{2}}
$$

where $C_{0}$ is a constant parameter, $\Omega$ the area of an individual grid cell, and $P_{r}$ is the Prandtl number. $C_{0}$ is, for example, selected as 0.1 and 0.28 by Shi et al. (2011) and Zhao et al. (2015), respectively, to configure hydrodynamic model in JZB. Given that $\Omega$ in the 2013 scenarios was lower than in the other scenarios, $A_{\mathrm{h}}$ calculated from the Smagorinsky scheme could affect the RT and the comparison of the scenarios representing different human pressures. To gain insight into this hypothesis, we carried out a sensitivity analysis in which we compared the basin and local RT with: (1) a $C_{0}$ of 0.2 in the Smagorinsky scheme; (2) a $C_{0}$ of 1.0 in the Smagorinsky scheme; (3) a constant $A_{\mathrm{h}}$ of $3 \mathrm{~m}^{2} / \mathrm{s}$; (4) a constant $A_{\mathrm{h}}$ of $10 \mathrm{~m}^{2} / \mathrm{s}$. We used the model configuration of the 2008 scenarios for this analysis. Given that more than $85 \%$ of the $A_{\mathrm{h}}$ values from the Smagorinsky scheme lay in the range $1-5 \mathrm{~m}^{2} / \mathrm{s}$, the constant value of $3 \mathrm{~m}^{2} / \mathrm{s}$ is a sensible choice to use in this study. 


\section{Results and discussion}

\subsection{Effects of grid size on residence time}

\subsubsection{Comparability of results from coarse and fine grids}

The results of the comparison between Grid F and C (Section 3.4) are shown in Fig. 2. The RTMs in the inner bay were almost identical $\left(R^{2}=0.9997\right)$, so we can say that the basin waterexchange capacity was the same for Grids $\mathrm{F}$ and $\mathrm{C}$. The distributions of local RT were also virtually the same for both cases (Figs. 2b,c). Some slight differences appeared in the west of the bay, but the total regional RT in this area were very similar: 66 days for Grid F, 64 days for Grid C (Figs. 2b,c). A 2-day difference is considered acceptable. Therefore, the results of the scenarios from 1935 to 2008 with coarser grids can be directly compared with those of the 2013 scenarios with finer grids. Note that this assertion can be only applied to the model results in this paper, and is not a general conclusion about numerical calculations with different model resolutions. 

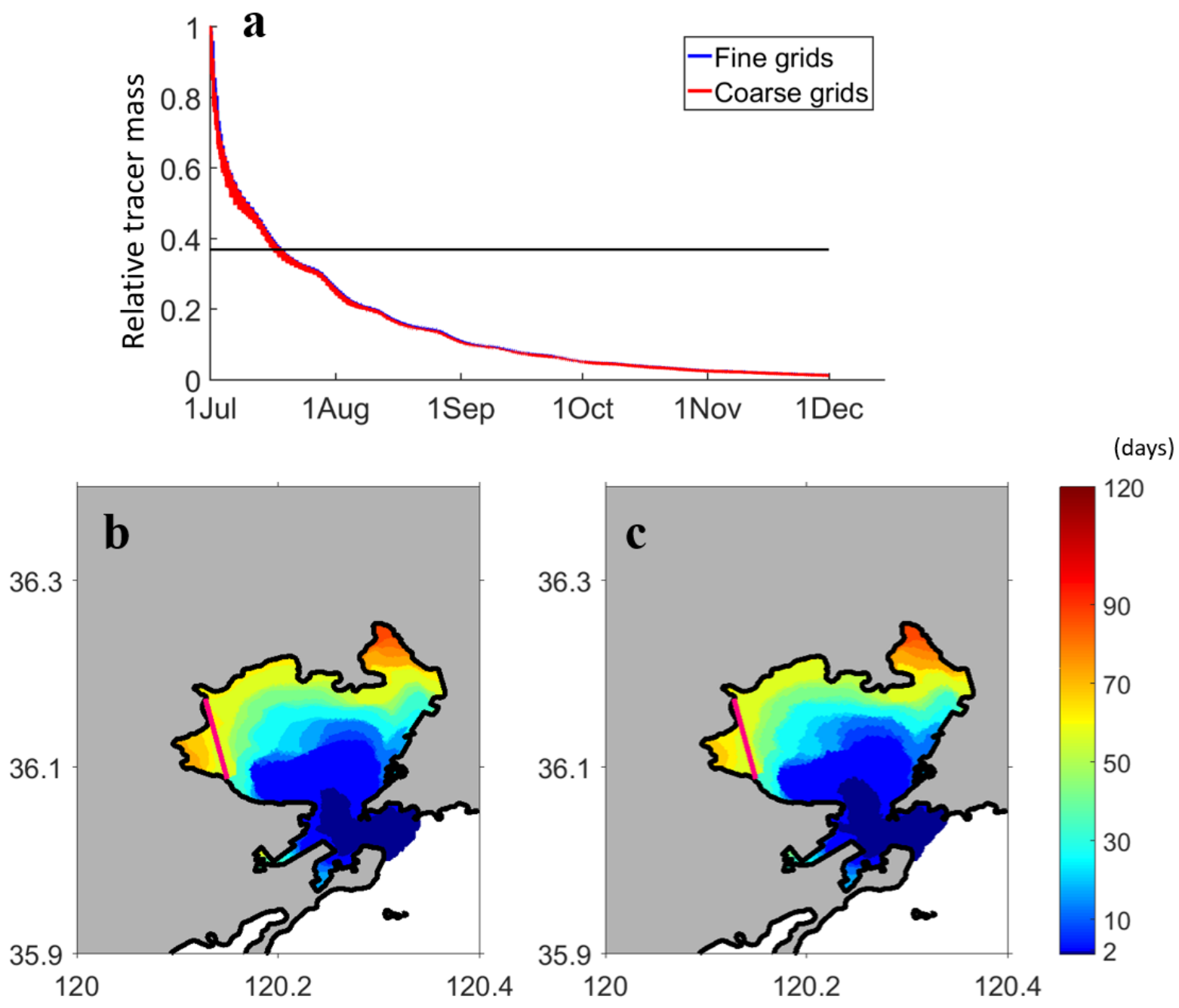

Fig. 2. The 2013 scenario without the bridge. (a) Relative tracer mass in the inner bay with fine and coarse grids. Distributions of local residence time with (b) the fine grid and (c) the coarse grid. The west region is delineated by the magenta line in (b) and (c).

\subsubsection{Effects of the horizontal diffusion coefficient on residence time}

The four different schemes in Section 3.5 led to similar rates of change in the concentration of total passive tracer, with a difference in the basin RT of only 1 day (Fig. 3a). Generally, no matter which method was used to determine $A_{\mathrm{h}}$, the distribution pattern of the local RT was the same: the contour lines of the local RT in the inner bay were approximately parallel to the 
coastline, and the northeast region had the worst water-exchange capacity, followed by the west region (Figs. 3b-e).

Figure 4 shows the averages and standard deviations of the local RT at each grid point from these four schemes in three regions: the west, the northeast, and the north-bridge regions. The standard deviations were mainly around 8 days in the three regions, reaching 33 days at some points. An $A_{\mathrm{h}}$ of $3 \mathrm{~m}^{2} / \mathrm{s}$ (red dots) provided medium RT values at the west and north-bridge regions, and the highest values in the northeast region. These results demonstrate that the calculation of local RT can be sensitive to the choice of $A_{\mathrm{h}}$. Therefore, the RT calculated from ocean models using different horizontal diffusion schemes and values should be compared with caution, even for model results of the same system. In this study, we used a constant dispersion coefficient $A_{\mathrm{h}}$ of $3 \mathrm{~m}^{2} / \mathrm{s}$ for all the scenarios, to make sure that the differences in the RT between the different scenarios were not affected by the grid resolution, but only by human interventions. 

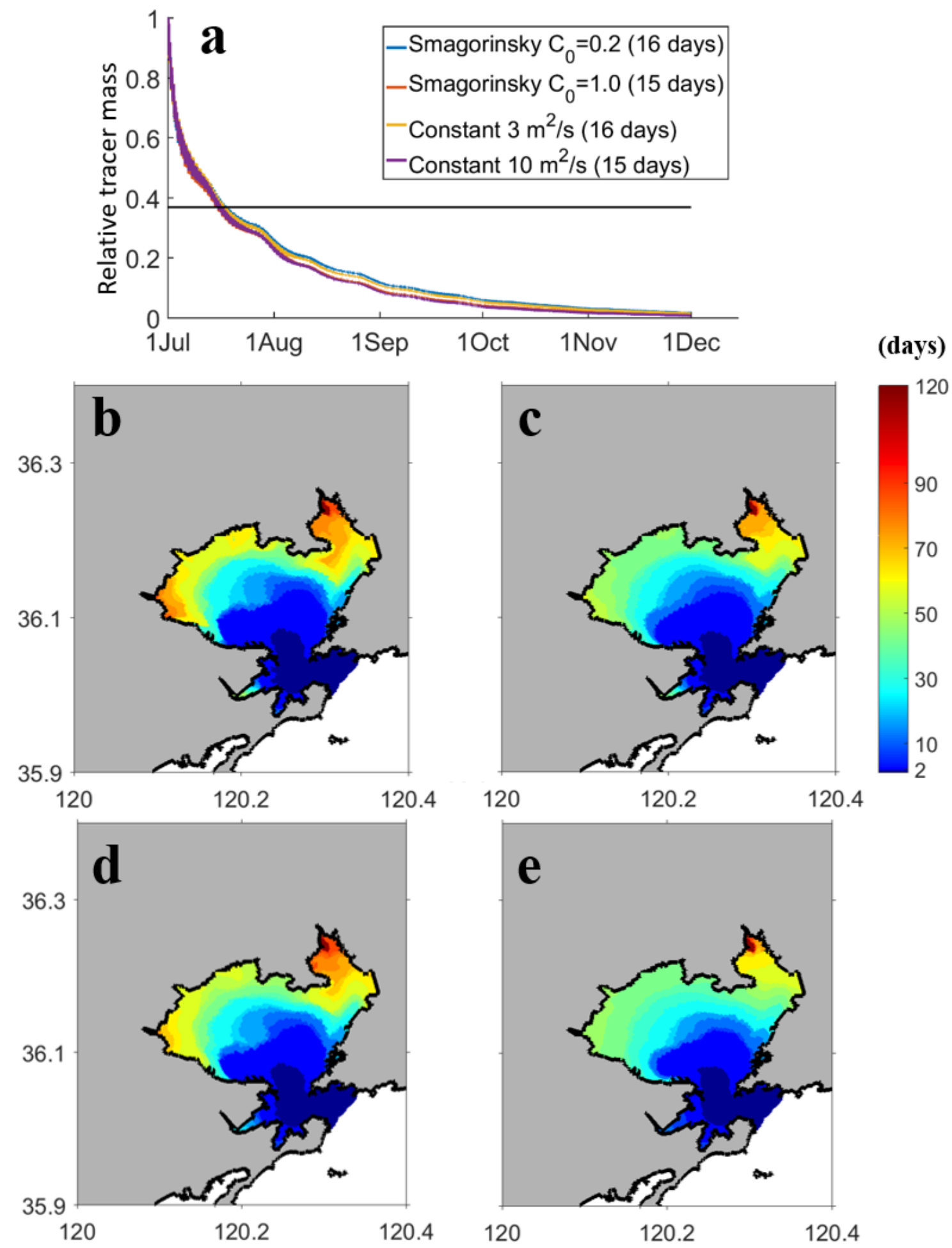

Fig. 3. (a) Relative tracer mass in the inner bay in 2008 from the four schemes of calculating $A_{\mathrm{h}}$, with the basin RT for each scheme shown in the legend. (b)-(d) Distributions of local RT in 2008 with $A_{\mathrm{h}}$ : (b) from the Smagorinsky scheme with $C_{0}=0.2 ;$ (c) from the Smagorinsky scheme with $C_{0}=1.0 ;(\mathbf{d})$ constant at 3 $\mathrm{m}^{2} / \mathrm{s}$; and (e) constant at $10 \mathrm{~m}^{2} / \mathrm{s}$. 

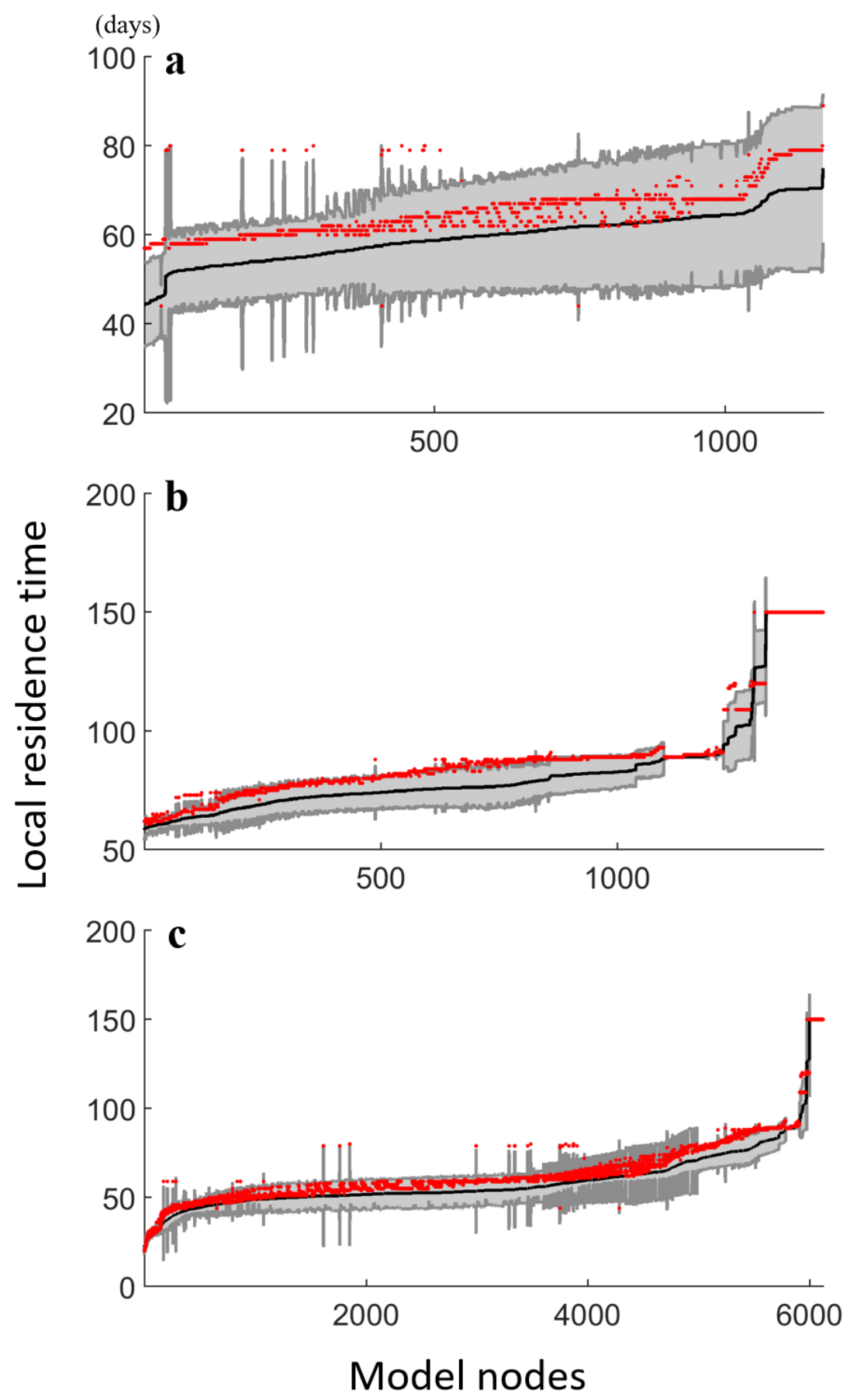

Fig. 4. Average (black dots) and standard deviation (grey-shaded bars) of the local RT at each grid point from the four schemes of calculating $A_{\mathrm{h}}$ in 2008 (a $C_{0}$ of 0.2 in the Smagorinsky scheme; a $C_{0}$ of 1.0 in the Smagorinsky scheme; a constant $A_{\mathrm{h}}$ of $3 \mathrm{~m}^{2} / \mathrm{s}$; a constant $A_{\mathrm{h}}$ of $10 \mathrm{~m}^{2} / \mathrm{s}$.) in the (a) west, (b) northeast and (c) north-bridge regions. Red dots show the values for $A_{\mathrm{h}}=3 \mathrm{~m}^{2} / \mathrm{s}$, the $A_{\mathrm{h}}$ used in the simulations. 


\subsection{Basin residence time}

The results calculated from the nine scenarios were classified into three groups, A, B, and C, to evaluate separately the impact of the different human interventions (Table 1).

Table 1. Groups of scenarios for comparison.

\begin{tabular}{|c|c|c|}
\hline Group & Scenario & Human intervention \\
\hline $\mathrm{A}$ & $\begin{array}{l}1935,1966,1986,2000,2008 \\
\text { and } 2013 \text { without the bridge }\end{array}$ & Land reclamation \\
\hline $\mathrm{B}$ & 1935,1935 Red Island reclaimed & Red Island reclamation \\
\hline $\mathrm{C}$ & $\begin{array}{l}\text { 2013: without the bridge; with the bridge; } \\
\text { with Red Island restored }\end{array}$ & $\begin{array}{l}\text { Bridge construction; Red } \\
\text { Island restoration }\end{array}$ \\
\hline
\end{tabular}

The basin RT was calculated for the three groups of scenarios. Figure 5 shows the evolution of the relative tracer mass (RTM, Eq. 2) over time and gives the corresponding basin RT. As the bay water containing the tracer was exchanged with shelf water, the RTM within JZB decreased roughly exponentially in all three groups of scenarios.

However, the RTM and therefore the basin RT (Table 2) were different in the scenarios of Group A. Basin RT increased slightly from 1935 (13 days) to 2000 (16 days), then remained constant from 2000 to 2013 (Fig. 5a). This suggests that the basin water-exchange capacity deteriorated from 1935 to 2000 due to the significant land reclamation, then remained stable from 2000 to 2013 because the reclamation was then on a smaller scale. The RTM in 2013 after around one month was marginally smaller than that in 2000 . This suggests that the coastal changes after 2000 also affected the flushing efficiency, but only to a minor extent; this is discussed further in Section 4.3. 

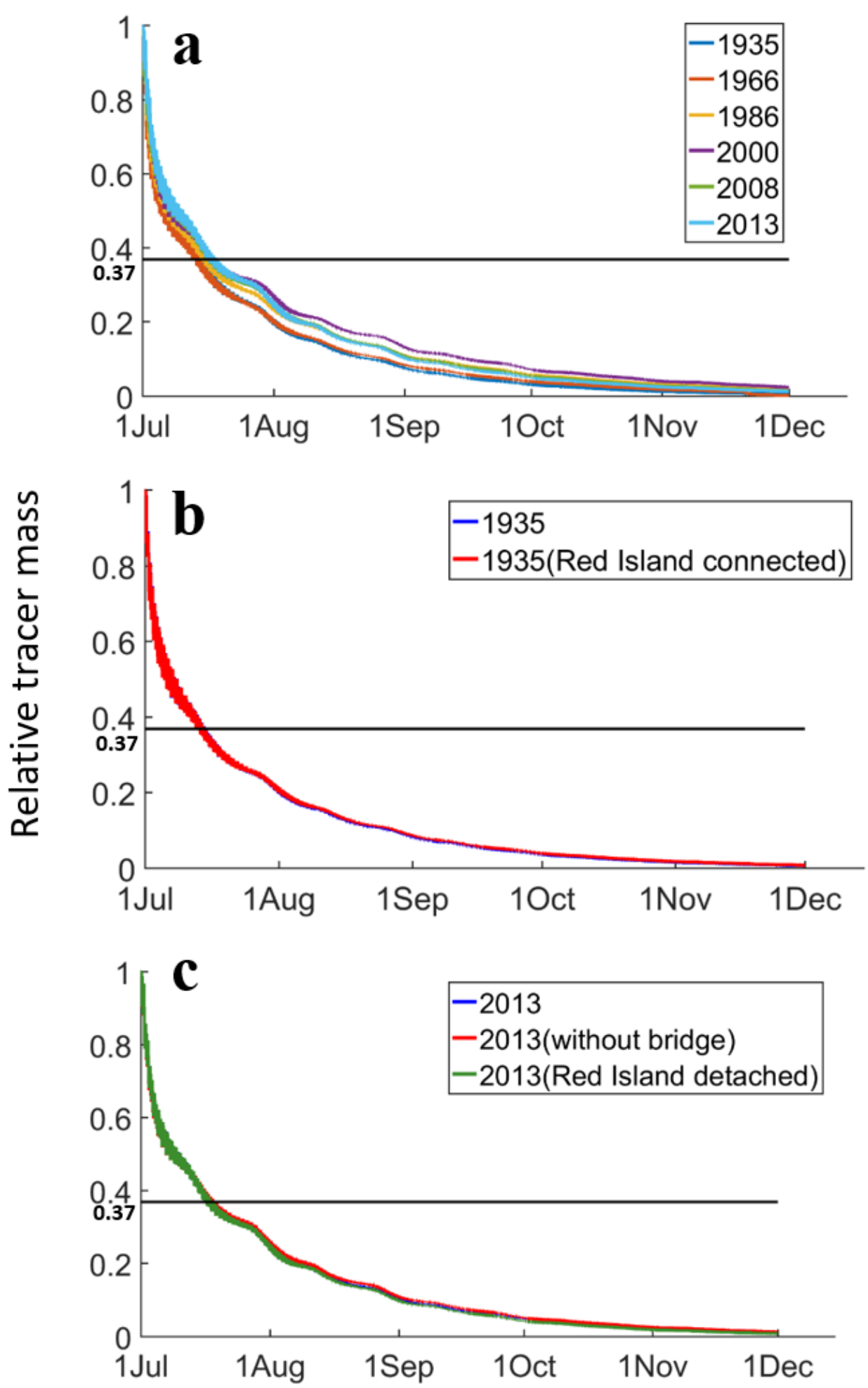

Fig. 5. Relative tracer mass in the inner bay showing the effects of: (a) land reclamation from 1935 to 2013; (b) Red Island reclamation in 1935; (c) with Red Island detached again and the bridge in 2013. The black lines show the threshold RTM of 0.37 (37\%). 
Table 2. Comparisons of basin and regional residence time (days) in all scenarios. The scenarios in Group A are highlighted in shadow.

\begin{tabular}{ccccc}
\hline & Basin & West & Northeast & North-bridge \\
\hline 1935 no Red Island & 13 & 52 & 51 & 44 \\
1935 + Red Island & 13 & 48 & 49 & 41 \\
1966 & 13 & 59 & 62 & 52 \\
1986 & 15 & 67 & 87 & 64 \\
2000 & 16 & 65 & 103 & 73 \\
2008 & 16 & 65 & 93 & 66 \\
2013 no bridge & 16 & 66 & 80 & 67 \\
2013 with bridge & 16 & 62 & 83 & 66 \\
2013 + Red Island & 16 & 68 & 60 & 59 \\
\hline
\end{tabular}

The RTMs were almost identical for all the scenarios of Group B, characterized by a basin RT of 13 days (Fig. 5b); the connecting of Red Island to the mainland in 1935 therefore had little impact on the basin water exchange in JZB. The RTM evolution and basin RT were also similar for all the scenarios of Group C (16 days), suggesting that the bridge and the restoration of Red Island also hardly affected the basin water exchange.

\subsection{Local residence time}

Local and regional RT were calculated for the scenarios of each group to help understand the impact of human interventions on regional water renewal (Figs. 6,7, Table 2). In general, the local RT increased from the entrance (1-2 days) to the head (35-153 days) of the bay in all the scenarios, reaching the highest values (60-153 days) on the northeast coast (Figs. 6,7). Unlike the basin RT, the distributions of local RT changed significantly from 1935 to 1986, particularly in the inner bay, concurrent with the most drastic changes in the coastline (Fig. 1b). They then changed to a lesser extent from 1986 to 2013, when land reclamation was moderate. The northeast regional RT grew from 49 days in 1935 to 103 days in 2000 (up by 110\%), then declined to 80 days in 2013 (Table 2). The west regional RT increased by 40\% from 1935 (48 days) to 1986, then stayed stable at around 66 days until 2013 (Table 2). The regional RT at 
north bridge reached a maximum value of 73 days in 2000, then remained almost constant from 2008 to 2013 (66 days) (Table 2). In summary, the water-exchange capacity of the inner bay deteriorated significantly between 1935 to 1986 due to land reclamation.
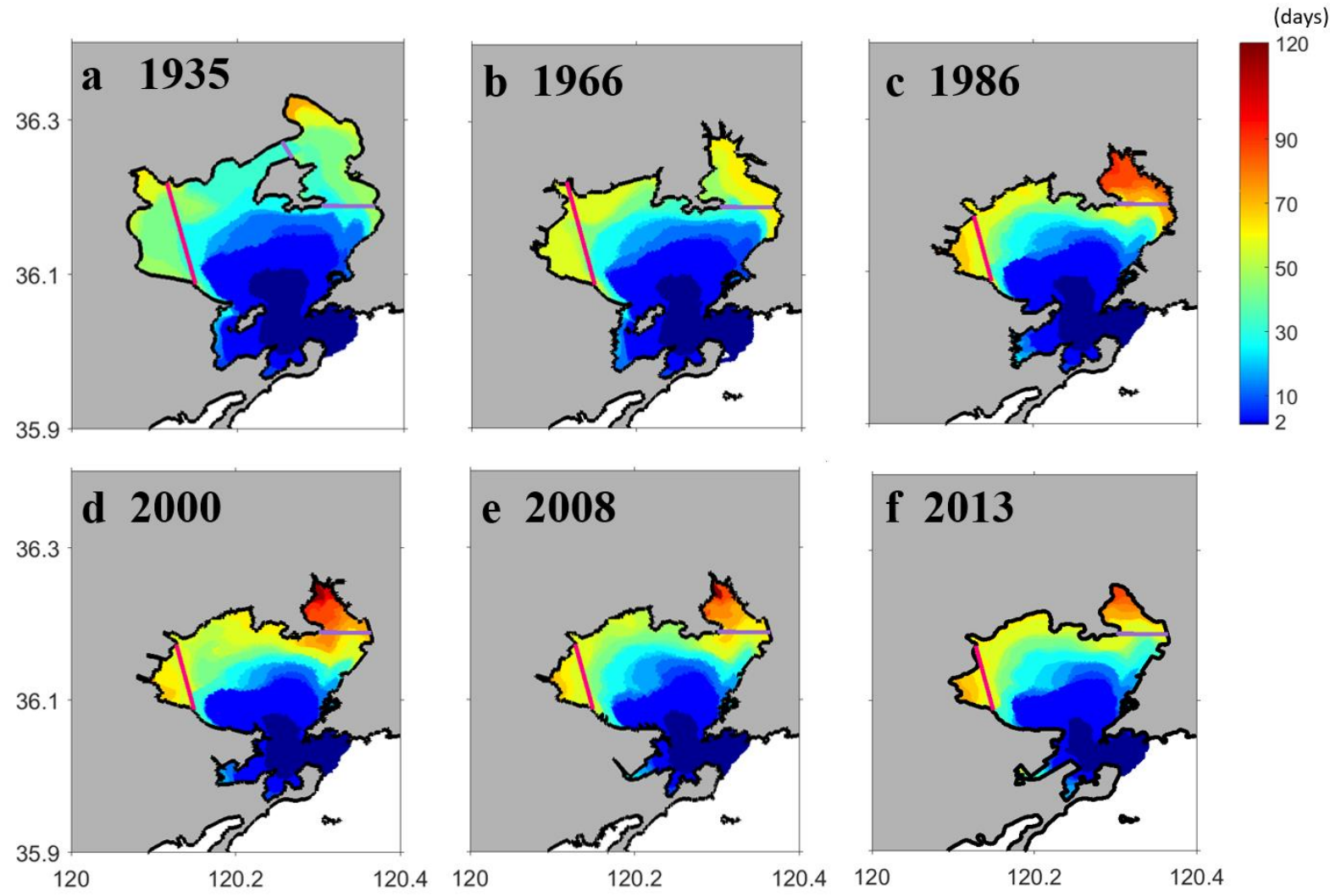

Fig. 6. Distributions of residence time for scenario: (a) in 1935; (b) in 1966; (c) in 1986; (d) in 2000; (e) in 2008; and (f) in 2013 without the bridge. The northeast and west regions are delineated by the purple and magenta lines, respectively. 


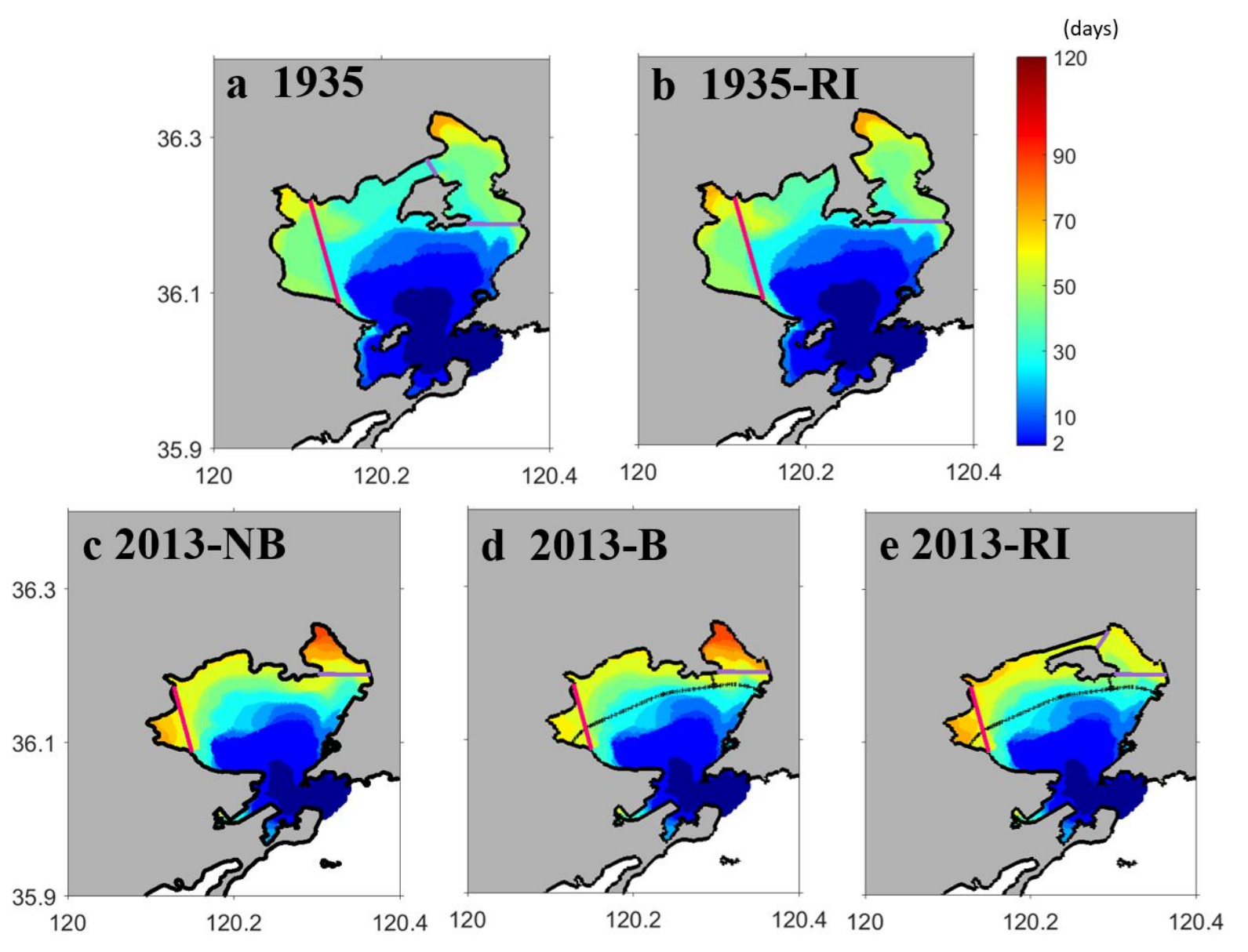

Fig. 7. Distributions of residence time for the scenario: (a) in 1935; (b) Red Island (RI) connected to the mainland in 1935; (c) no bridge (NB) in 2013; (d) with the bridge (B) in 2013; and (e) Red Island detached from the mainland in 2013. The northeast and west regions are delineated by the purple and magenta lines, respectively.

The local and regional RT also changed for the Red Island scenarios, but to different degrees in 1935 and 2013 (Fig. 7). The connection of the island to the mainland in 1935 increased the regional RT by $2-4$ days in all the inner regions (Figs. 7a,b, Table 2). A (hypothetical) disconnection of the island from the mainland in 2013 would have decreased the regional RT by 7 days and by 23 days in the north-bridge region and the northeast region, respectively, and increased it by 6 days in the west region (Figs. 7c-e, Table 2). Therefore, the plan to restore Red Island in the future would increase the water-exchange capacity in the northeast of JZB, a region highly affected by pollutant accumulation (Liu et al., 2005). 
Construction of the bridge increased the northeast regional RT from 80 days to 83 days, decreased the west RT from 66 days to 62 days, and did not change the RT in the north-bridge region (around 66 days) (Figs. 7c,d, Table 2). It therefore had only a minor impact on local and regional RT.

\subsection{Tidal prism}

Tidal prism is an important parameter in water-exchange capacity (Ketchum and Rawn, 1951). A larger tidal prism means that more water from the ocean enters the bay at high tide, and hence more water is flushed out from the bay at low tide. Figure 8, and Tables 3 and 4 show the multidecadal evolution of the regional tidal prism and regional RT in JZB for the three groups of scenarios. The tidal prism in the northeast and north-bridge regions declined by $66 \%$ and $46 \%$, respectively, from 1935 to 2000 , concurrent with the largest land reclamation, then remained roughly constant from 2000 to 2008 , finally increasing by $34 \%$ and $10 \%$, respectively, by 2013 (Figs. 8b,c).

In the west region (Fig. 8a), the tidal prism also decreased from 1935 to 1986 (by 61\%) and remained constant from that year. The decreasing trend in the tidal prism from 1935 to 2000 would explain the increasing values of the regional RT from 1935 to 2000 . The decrease in regional RT from 2008 to 2013 can also be regarded as a response to the increasing tidal prism. The correlation of tidal prism and regional RT was high in the three regions $\left(R^{2}=0.91-0.96\right)$.

The tidal prism experienced a significant increase in the northeast region from 1986 to 2013, despite the moderate changes to the coastline, because of the bathymetry changes during this period (Figs. 9e,g,I,k). The bathymetry was almost unchanged in the common area between 1935 and 1966 (Figs. 9a,c), with most of it underwater. However, the northern end of the northeast region was landfilled to around $1 \mathrm{~m}$ above sea level in 1986 (Fig. 9e) for a salt 
evaporation pond (Lei et al., 2013), then to more than $2 \mathrm{~m}$ above sea level in 2000 and 2008 (Figs. 9g,i). Following dredging from 2010 (Lei et al., 2013), this area was again underwater after 2013 (Fig. 9k). Landfill reduced the tidal prism and therefore increased the RT. The tidalenergy flux (calculated as in Song et al. (2013)) changed correspondingly (Figs. 9b,d,f,h,j,l), decreasing at the north end of the northeast region between 1986 and 2000 and increasing between 2008 and 2013 (Figs. 9f,h,j,l). This change could explain the decrease (increase) in the tidal prism during this period (Fig. 8b).
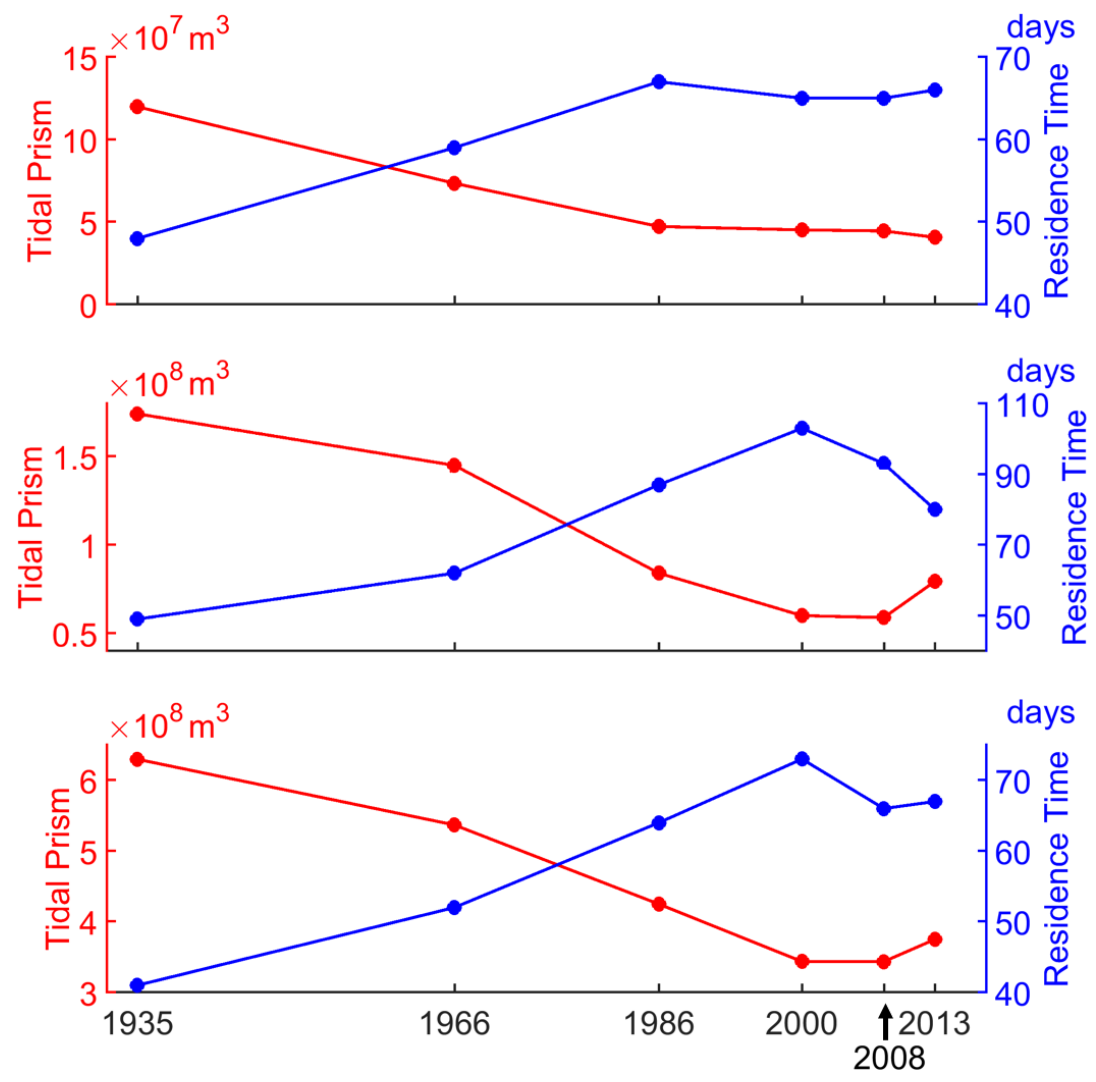

Fig. 8. Comparisons of tidal prism and regional RT from 1935 to 2013 for the: (a) west region; (b) northeast region; (c) north-bridge region. 
Table 3. Comparisons of tidal prism $\left(\mathrm{TP} \times 10^{8} \mathrm{~m}^{3}\right)$ and regional residence time (RT, days) in 1935 before and after Red Island was connected to the mainland.

\begin{tabular}{ccccccc}
\hline & \multicolumn{2}{c}{ West } & \multicolumn{2}{c}{ Northeast } & \multicolumn{2}{c}{ North bridge } \\
\hline & TP & RT & TP & RT & TP & RT \\
\hline 1935 + Red Island & 1.20 & 48 & 1.74 & 49 & 6.30 & 41 \\
No Red Island & 1.15 & 52 & 1.80 & 51 & 6.32 & 44 \\
\hline
\end{tabular}

Table 4. Comparisons of tidal prism $\left(\mathrm{TP} \times 10^{8} \mathrm{~m}^{3}\right)$ and regional residence time (RT, days) in 2013 with no bridge, with the bridge, and with the bridge and Red Island disconnected from the mainland.

\begin{tabular}{ccccccc}
\hline & \multicolumn{2}{c}{ West } & \multicolumn{2}{c}{ Northeast } & \multicolumn{2}{c}{ North bridge } \\
\hline & TP & RT & TP & RT & TP & RT \\
\hline No bridge & 0.41 & 66 & 7.93 & 80 & 3.75 & 67 \\
With bridge & 0.41 & 62 & 7.92 & 83 & 3.77 & 66 \\
+ Red Island & 0.41 & 68 & 8.39 & 60 & 3.97 & 59 \\
\hline
\end{tabular}



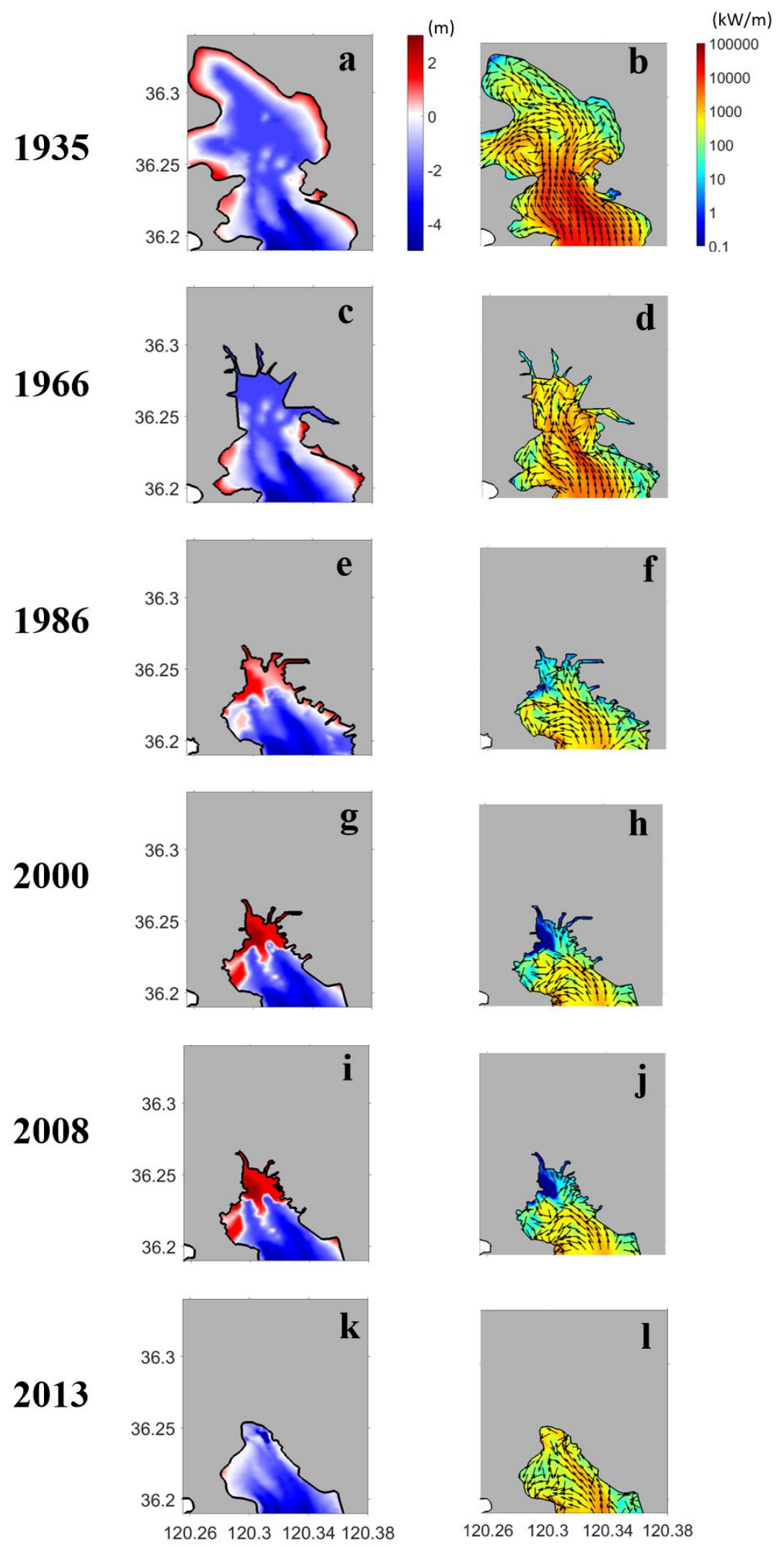

Fig. 9. Distributions of bathymetry $(\mathbf{a}, \mathbf{c}, \mathbf{e}, \mathbf{g}, \mathbf{i}, \mathbf{k})$ and tidal-energy flux $(\mathbf{b}, \mathbf{d}, \mathbf{f}, \mathbf{h}, \mathbf{j}, \mathbf{l})$ for the scenario: (a, b) in 1935; (c, d) in 1966; (e, f) in 1986; (g, h) in 2000; (i, j) in 2008; and $(\mathbf{k}, \mathbf{l})$ in 2013. Arrows show the direction, colours the magnitude of the tidal-energy flux. 
Changes in the tidal prism could also explain the changes in the regional RT for the Red Island scenarios. The connection of Red Island to the mainland in 1935 caused a slight growth in the tidal prism in the northeast (3\%) and north-bridge regions $(0.3 \%)$, but a decrease of $8 \%$ in the west region (Table 3). Concurrently, the regional RT increased by 2-4 days in all three regions. Restoration of Red Island in 2013 would have increased the tidal prism by $5 \%$ in both the northeast and the north-bridge regions, where both the regional RT were significantly shorter, but would have had a very limited effect on the tidal prism in the west region (Table 4). The tidal prism was hardly changed by the bridge construction in all three areas, as was the case for the regional RT. In summary, the tidal prism correlated negatively and significantly with regional RT in JZB, especially when the largest land reclamation occurred.

Tidal prism changes have also occurred in other human-impacted coasts. For example, land reclamation decreased tidal prism by approximately $18 \%$, as well as current velocities between 1847 and 1994 in the Ribble Estuary, northwest England (Van Der Wal et al., 2002). In the Yangtze River estuary in China, the elevation of shoals led to a reduction of $43 \%$ in the tidal prism between 1997 and 2010 (Zhang et al., 2018), similar to the changes in the north-east of JZB between 1935 to 1986 .

\subsection{Residual currents}

The residual currents at each grid point were calculated as the time-averaged velocities over one tidal cycle (Lee and Beardsley, 1999), then compared in the scenarios of each group to determine their effect on the transport of passive tracers and the water-exchange capacity (Figs. 10,11). As the model was forced only by tides, the differences in the residual currents between the scenarios depended only on the nonlinear effect of the flow patterns over the changing coastline. 
Residual currents were less than $0.10 \mathrm{~m} / \mathrm{s}$ in most of the inner bay in most scenarios, but higher in 1935 , particularly in the northeast $(0.34 \mathrm{~m} / \mathrm{s})$ and west $(0.2 \mathrm{~m} / \mathrm{s})$ regions (Fig. 10a). The significant decrease in residual currents from 1935 to 1966 would explain the increase in the regional RT during this period, concurrent with the decrease in tidal prism, as discussed in Section 4.3. The residual currents featured three eddies (one anticyclonic between two cyclonic) at the entrance to the bay in all scenarios (red circles in Fig. 10a). The maximum velocities in the eddy system again deceased from 1935 to 1986 , from $0.53 \mathrm{~m} / \mathrm{s}$ to $0.42 \mathrm{~m} / \mathrm{s}$ according to the model results. This would have reduced the transport from the inner bay to the ocean, and therefore contributed to the increase in the regional RT during this period (Fig. 8). A contribution of tidal-induced residual currents and eddies to the water exchange has been found in several coastal areas such as the Seto Inland Sea in Japan (Sugimoto, 1975), the Tagus Estuary in Portugal (Fortunato et al., 1997), Qiongzhou Strait in China (Chen et al., 2009), and Puget Sound in the USA (Yang and Wang, 2013). However, no study has looked at the longterm evolution of these processes.

The connection of Red Island to the mainland in 1935 did not change the residual currents in the bay (Figs. 11a,b). The hypothetical detachment of Red Island in 2013 would enable water transfer between the two sides of the island, with an increase in the residual currents, particularly in the northeast region (up to $0.24 \mathrm{~m} / \mathrm{s}$, Fig. 11e). These higher currents would also help to decrease the regional RT in this area. The patterns of residual currents were almost the same before and after the bridge construction (Figs. 11c,d), suggesting a limited effect of this structure on the residual currents. 

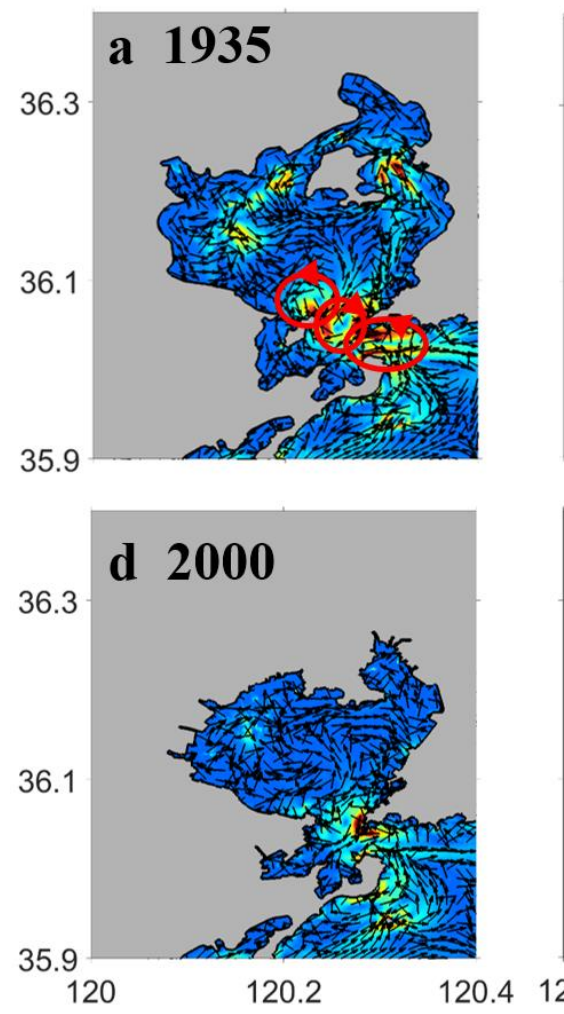
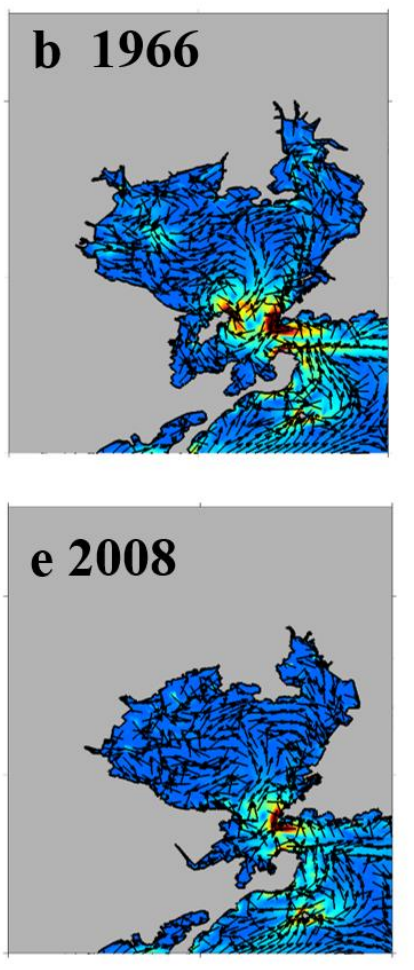
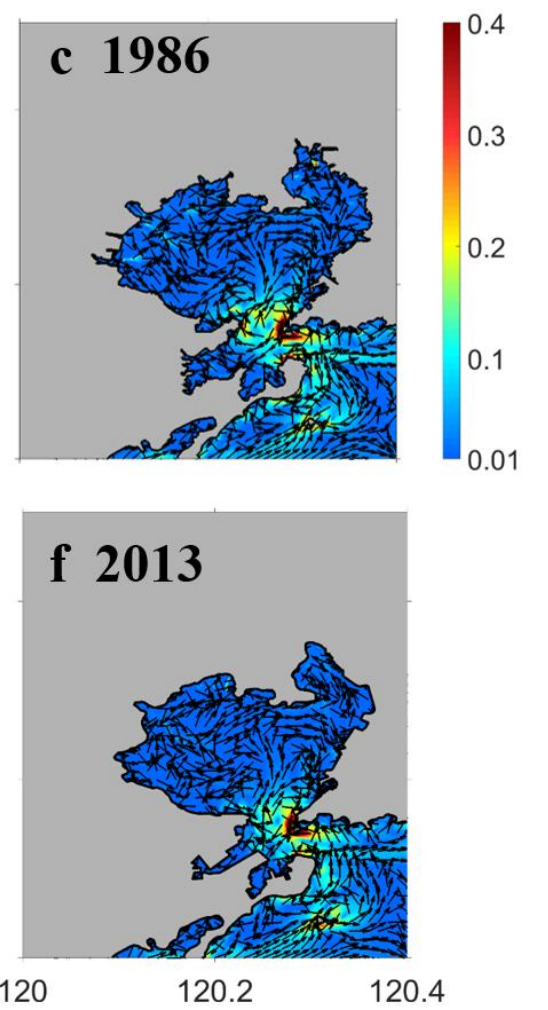

Fig. 10. Distributions of residual currents for the scenario: (a) in 1935; (b) in 1966; (c) in 1986; (d) in 2000; (e) in 2008; and (f) in 2013 without the bridge. Arrows show the direction, colours the magnitude. The red arrows in (a) show the direction of the three residual-current eddies. 

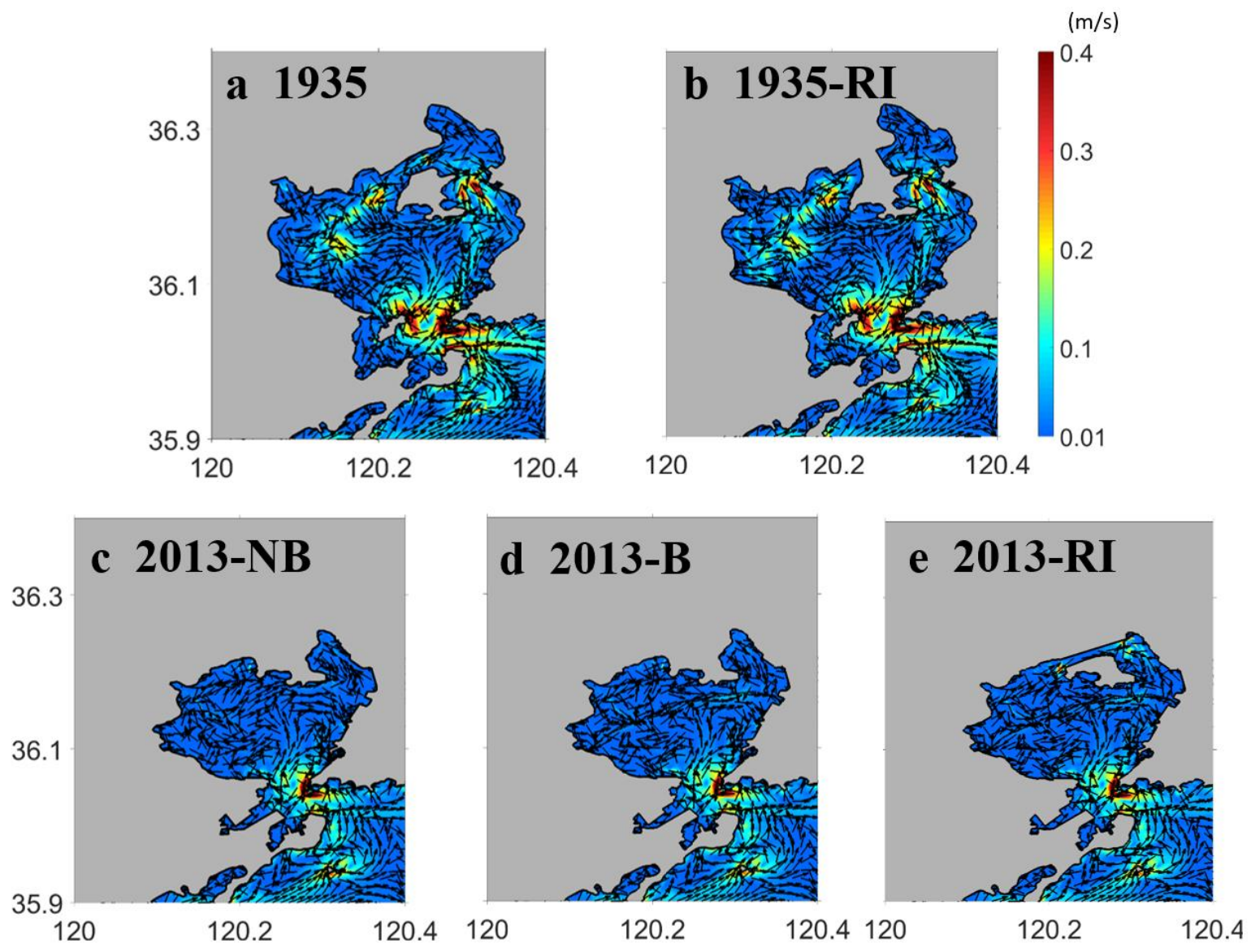

Fig. 11. Distributions of residual currents for the scenario: (a) in 1935; (b) in 1935 with Red Island (RI) connected to the mainland; (c) in 2013 with no bridge (NB); (d) in 2013 with the bridge (B); (e) in 2013 with Red Island (RI) detached from the mainland. Arrows show the direction, colours the magnitude.

\subsection{Comparison with previous studies in Jiaozhou Bay}

Although this is the first paper that systematically investigated the impact of all the human interventions on the JZB water-exchange capacity, several studies have previously quantified the renewal capacity of the bay. Liu et al. (2004) compared previous studies, and found that the timescale and methodology used to describe water exchange led to different estimates. Here, we found that model values for the horizontal diffusion coefficient can affect the estimation of RT. Chen et al. (2019) estimated that the basin half-life time in 2015 was around 10 days, the same order of magnitude of the basin RT estimated in this paper (16 days in 2013). However, 
Shi et al. (2011) and Liu et al. (2004) estimated water-exchange indices of 40 and 56 days, respectively. Unlike the present work, these studies used a coarser rectangular grid, which may have impacted their results (similar to an example illustrated by Yuan et al. (2019b)). There is no information about $A_{\mathrm{h}}$ configuration in Liu et al. (2004), but Shi et al. (2011) used Smagorinsky scheme by setting $C_{0}$ as 0.1 , which may also be the reason for the discrepancy. We cannot tell which study is the most accurate, because (1) each study uses a different methodology to calculate the water-exchange capacity; (2) it is beyond the scope of this paper to determine a universal $A_{\mathrm{h}}$ and to evaluate the calculation of RT in previous work. The objective of this paper is to analyse the relative variability of residence time over the last decades, highlighting the anthropogenic effects.

Regarding the regional distribution of RT, Shi et al. (2011) also found the highest values in the northeast region, and that land reclamation between the 1960s and 2000s reduced the tidal prisms and increased the RT, in agreement with the results of the present study.

\section{Conclusion}

Our study has investigated how land reclamation, the construction of a cross-bay bridge, and the restoration of Red Island have modified the water-exchange capacity of a semi-enclosed bay, Jiaozhou Bay (JZB) in northern China. A hydrodynamic model coupled with an Eulerian tracer-tracking module was used to model various historical scenarios and calculate the basin and local residence time (RT). The longer the RT, the longer it takes for pollutants to be cleared from the bay by the tides.

Land reclamation tends to increase the RT over the decades. The effects were moderate on the basin RT but significant in the inner regions of the bay. The regional effects of land reclamation in JZB can be classified into two stages. From 1935 to 1986, the largely modified coastline led to a strong deterioration in the water-exchange capacity: RT increased by $77 \%, 56 \%$, and $40 \%$ 
in the northeast, north-bridge and west regions, respectively. In the period 1986 to 2013, when land reclamation was more moderate, the regional RT continued to increase up to 2000 in the northeast and north-bridge regions, then decreased slightly. The dramatic decrease of tidal prism and residual-current velocities between 1935 and 1986 may have also contributed to the increase in the regional RT.

The JZB Bridge construction had only a limited impact on the basin and local water-exchange capacity, the tidal prism and the residual currents. Restoration of Red Island would also have a limited effect on the basin water-exchange capacity of the bay but would improve waterexchange capacity in the northeast region, with a decrease from 83 to 60 days in the regional $\mathrm{RT}$; the west region RT would be subject to a small increase of 6 days.

The local RT, but not the basin RT, was sensitive to the choice of the horizontal diffusion coefficient $A_{\mathrm{h}}$ in the numerical simulations. $A_{\mathrm{h}}$ from the Smagorinsky scheme can also be affected by the grid resolution; this should be carefully considered, especially when comparing results from models using different resolutions. Further work should be directed to estimating and validating a reasonable range of $A_{\mathrm{h}}$ for use in future simulations of JZB.

This paper provides valuable results for researchers interested in the transport of pollutants, as well as for governments and managers planning to develop marine activities. For example, the high RT of the northeast could make it a trap for pollutants and lead to the water eutrophication. Although the restoration of Red Island would improve pollutant removal in the northeast region, it would be far from enough to return the removal efficiency to its original level. Further intervention is required, such as reversing the landfill and addressing the pollutant problem at sources. 


\section{Acknowledgements}

This is publication No. 88 of the Sino-Australian Research Consortium for Coastal Management (previously the Sino-Australian Research Centre for Coastal Management). This paper benefited from editorial review by Dr Peter McIntyre from UNSW Canberra, and two anonymous reviewers whose comments have further improved this paper. Y. Yuan is supported by the China Scholarship Council and a UNSW Canberra Top-up Scholarship.

\section{References}

Banas, N. and Hickey, B., 2005. Mapping exchange and residence time in a model of Willapa Bay, Washington, a branching, macrotidal estuary. Journal of Geophysical Research: Oceans, 110(C11): $1-20$

Berntsen, J., 2002. Internal pressure errors in sigma-coordinate ocean models. Journal of Atmospheric and Oceanic Technology, 19(9): 1403-1414

Chen, C., Beardsley, R., Cowles, G., Qi, J., Lai, Z., Gao, G., Stuebe, D., Xu, Q., Xue, P. and Ge, J., 2013. An Unstructured Grid, Finite-Volume Community Ocean Model FVCOM User Manual, SMAST/UMASSD-13-0701, 416 pp.

Chen, C., Ji, R., Zheng, L., Zhu, M. and Rawson, M., 1999. Influences of physical processes on the ecosystem in Jiaozhou Bay: a coupled physical and biological model experiment. Journal of Geophysical Research: Oceans, 104(C12): 29925-29949

Chen, C., Li, P., Shi, M., Zuo, J., Chen, M. and Sun, H., 2009. Numerical study of the tides and residual currents in the Qiongzhou Strait. Chinese Journal of Oceanology and Limnology, 27(4): 931

Chen, C., Liu, H. and Beardsley, R.C., 2003. An unstructured grid, finite-volume, three-dimensional, primitive equations ocean model: application to coastal ocean and estuaries. Journal of Atmospheric and Oceanic Technology, 20(1): 159-186 
Chen, J. and Chen, X., 2012. Numerical simulation of the hydrodynamic evolution of the Jiaozhou Bay in the last 70 years. Acta Oceanologica Sinica, 34(6): 30-41

Chen, Y., Song, D., Bao, X.W. and Yan, Y., 2019. Impact of the cross-bay bridge on water exchange in Jiaozhou Bay, Qingdao, China. Oceanologia et Limnologia Sinica, 50(4): 707-718 (in Chinese with English abstract)

Cheng, Z., Jalon-Rójas, I., Wang, X.H. and Liu, Y., 2020. Impacts of land reclamation on sediment transport and sedimentary environment in a macro-tidal estuary. Estuarine, Coastal and Shelf Science, 242(106861): 1-21

Cui, B., He, Q., Gu, B., Bai, J. and Liu, X., 2016. China's coastal wetlands: understanding environmental changes and human impacts for management and conservation. Wetlands, 36: S1-S9

Diaz, R.J. and Rosenberg, R., 2008. Spreading dead zones and consequences for marine ecosystems. Science, 321(5891): 926-929

Dong, Z., Lou, A. and Cui, L., 2010. Assessment of eutrophication of Jiaozhou Bay. Marine Sciences, 34(12): 36-39 (in Chinese with English abstract)

Ferrarin, C., Ghezzo, M., Umgiesser, G., Tagliapietra, D., Camatti, E., Zaggia, L. and Sarretta, A., 2013. Assessing hydrological effects of human interventions on coastal systems: numerical applications to the Venice Lagoon. Hydrology and Earth System Sciences, 17(5): 1733-1748

Fortunato, A., Baptista, A.M. and Luettich Jr, R.A., 1997. A three-dimensional model of tidal currents in the mouth of the Tagus estuary. Continental Shelf Research, 17(14): 1689-1714

Gao, G.D., Wang, X.H. and Bao, X.W., 2014. Land reclamation and its impact on tidal dynamics in Jiaozhou Bay, Qingdao, China. Estuarine, Coastal and Shelf Science, 151: 285-294

Gong, W., Shen, J. and Jia, J., 2008. The impact of human activities on the flushing properties of a semi-enclosed lagoon: Xiaohai, Hainan, China. Marine Environmental Research, 65(1): 62-76

Gordon, C.T. and Stern, W.F., 1982. A description of the GFDL global spectral model. Monthly Weather Review, 110(7): 625-644

Grell, G.A., Dudhia, J. and Stauffer, D.R., 1994. A description of the fifth-generation Penn State/NCAR Mesoscale Model (MM5), University Corporation for Atmospheric Research, 122 pp.

Hancock, G.J., Webster, I.T. and Stieglitz, T.C., 2006. Horizontal mixing of Great Barrier Reef waters: Offshore diffusivity determined from radium isotope distribution. Journal of Geophysical Research: Oceans, 111(C12): 1-14

Jia, H., Shen, Y., Su, M. and Yu, C., 2018. Numerical simulation of hydrodynamic and water quality effects of shoreline changes in Bohai Bay. Frontiers of Earth Science, 12(3): 625-639

Kenov, I.A., Garcia, A.C. and Neves, R., 2012. Residence time of water in the Mondego estuary (Portugal). Estuarine, Coastal and Shelf Science, 106: 13-22

Ketchum, B.H. and Rawn, A., 1951. The flushing of tidal estuaries [with discussion]. Sewage and Industrial Wastes, 23(2): 198-209 
Lee, S.H. and Beardsley, R.C., 1999. Influence of stratification on residual tidal currents in the Yellow Sea. Journal of Geophysical Research: Oceans, 104(C7): 15679-15701

Lei, N., Hu, X. and Zhou, X., 2013. Evolution process and ecological effect analysis of reclamation in Jiaozhou Bay. Marine Environmental Science, 32(4): 506-509 (in Chinese with English abstract)

Li, P., Li, G., Qiao, L., Chen, X., Shi, J., Gao, F., Wang, N. and Yue, S., 2014. Modeling the tidal dynamic changes induced by the bridge in Jiaozhou Bay, Qingdao, China. Continental Shelf Research, 84: 43-53

Liang, S.-k., Pearson, S., Wu, W., Ma, Y.-j., Qiao, L.-1., Wang, X.H., Li, J.-m. and Wang, X.-1., 2015. Research and integrated coastal zone management in rapidly developing estuarine harbours: a review to inform sustainment of functions in Jiaozhou Bay, China. Ocean \& Coastal Management, 116: 470-477

Lin, H., Chen, Z., Hu, J., Cucco, A., Zhu, J., Sun, Z. and Huang, L., 2017. Numerical simulation of the hydrodynamics and water exchange in Sansha Bay. Ocean Engineering, 139: 85-94

Liu, R., 1992. The characteristics of natural environment. In: R. Liu (Ed.), Ecology and Living Resources of Jiaozhou Bay. Science Press, Beijing, pp. 2-3 (in Chinese)

Liu, S.M., Zhang, J., Chen, H.T. and Zhang, G.S., 2005. Factors influencing nutrient dynamics in the eutrophic Jiaozhou Bay, North China. Progress in Oceanography, 66(1): 66-85

Liu, Z., Wei, H., Liu, G. and Zhang, J., 2004. Simulation of water exchange in Jiaozhou Bay by average residence time approach. Estuarine, Coastal and Shelf Science, 61(1): 25-35

Lv, X.-g., Zhao, C., Xia, C.-s. and Qiao, F.-1., 2010. Numerical study of water exchange in the Jiaozhou Bay and the tidal residual currents near the bay mouth. Acta Oceanologica Sinica, 32(2): 2030 (in Chinese with English abstract)

Okada, T., Nakayama, K., Takao, T. and Furukawa, K., 2011. Influence of freshwater input and bay reclamation on long - term changes in seawater residence times in Tokyo Bay, Japan. Hydrological Processes, 25(17): 2694-2702

Ostroumov, S., 2006. Biomachinery for maintaining water quality and natural water self-purification in marine and estuarine systems: elements of a qualitative theory. International Journal of Oceans and Oceanography, 1(1): 111-118

Patgaonkar, R.S., Vethamony, P., Lokesh, K. and Babu, M., 2012. Residence time of pollutants discharged in the Gulf of Kachchh, northwestern Arabian Sea. Marine Pollution Bulletin, 64(8): $1659-1666$

Qian, G., Han, H., Liu, J., Liang, S., Shi, X. and Wang, X., 2009. Spatiotemporal changes of main chemical pollutants for the last thirty years in the Jiaozhou Bay. Period Ocean Univ China, 39(4): 781-788 (in Chinese with English abstract)

Qiao, L., Liang, S., Song, D., Wu, W. and Wang, X.H., 2019. Jiaozhou Bay, Sediment Dynamics of Chinese Muddy Coasts and Estuaries. Elsevier, pp. 5-23 
Safak, I., Wiberg, P., Richardson, D. and Kurum, M., 2015. Controls on residence time and exchange in a system of shallow coastal bays. Continental Shelf Research, 97: 7-20

Sheng, M., Cui, J., Shi, Q., Li, L. and Geng, Y., 2014. Analysis of sediment discharge characteristics of Rivers in Jiaozhou Bay, Qingdao City. Journal of China Hydrology, 34(3): 93-96 (in Chinese with English abstract)

Shi, J., Li, G. and Wang, P., 2011. Anthropogenic influences on the tidal prism and water exchanges in Jiaozhou Bay, Qingdao, China. Journal of Coastal Research, 27(1): 57-72

Smagorinsky, J., 1963. General circulation experiments with the primitive equations: I. The basic experiment. Monthly Weather Review, 91(3): 99-164

Smith, V.H., 2003. Eutrophication of freshwater and coastal marine ecosystems a global problem. Environmental Science and Pollution Research, 10(2): 126-139

Song, D., Wang, X.H., Zhu, X. and Bao, X., 2013. Modeling studies of the far-field effects of tidal flat reclamation on tidal dynamics in the East China Seas. Estuarine, Coastal and Shelf Science, 133: $147-160$

Sugimoto, T., 1975. Effect of boundary geometries on tidal currents and tidal mixing. Journal of the Oceanographical Society of Japan, 31(1): 1-14

Sun, L., Wang, Y. and Liu, X., 2016. A study on main pollutants flux of Jiaozhou Bay in 2015. Journal of Environmental Management College of China, 26(6): 66-69 (in Chinese with English abstract)

Sun, Y.-J., Jalón-Rojas, I., Wang, X.H. and Jiang, D., 2018. Coastal upwelling by wind-driven forcing in Jervis Bay, New South Wales: A numerical study for 2011. Estuarine, Coastal and Shelf Science, 206: 101-115

Takeoka, H., 1984. Fundamental concepts of exchange and transport time scales in a coastal sea. Continental Shelf Research, 3(3): 311-326

Tosic, M., Martins, F., Lonin, S., Izquierdo, A. and Restrepo, J.D., 2019. Hydrodynamic modelling of a polluted tropical bay: Assessment of anthropogenic impacts on freshwater runoff and estuarine water renewal. Journal of Environmental Management, 236: 695-714

Van Der Wal, D., Pye, K. and Neal, A., 2002. Long-term morphological change in the Ribble Estuary, northwest England. Marine Geology, 189(3-4): 249-266

Wang, C., Zhang, X.-Q. and Sun, Y.-L., 2009. Numerical simulation of water exchange characteristics of the Jiaozhou Bay based on a three-dimensional Lagrangian model. China Ocean Engineering, 23(2): $277-290$

Wang, X. and Li, K., 2006. The seaward discharge of primary pollutants in Jiaozhou Bay. In: X. Wang, K. Li and X. Shi (Eds.), The Marine Environmental Capacity of Primary Pollutants in Jiaozhou Bay. Science Press, Beijing, pp. 3-22 (Chinese) 
Wu, Y., Wang, C., Zhang, Y., Zhang, Q. and Weng, X., 1992. Water exchange and diffusion. In: R. Liu (Ed.), Ecology and Living Resources of Jiaozhou Bay. Science Press, Beijing, pp. 57-72 (in Chinese)

Xing, F., Sun, J., Li, Y., Yuan, D. and Tao, J., 2013. Numerical simulation of water exchange in Bohai Sea with age and half-life time. Proceedings of the 35th International Association for HydroEnvironment Engineering and Research World Congress, Chengdu, China, pp. 8-13.

Yang, D., Miao, Z., Xu, H., Chen, Y. and Sun, J., 2013. Jiaozhou Bay water exchange time. Marine Environmental Science, 32(3): 372-380 (in Chinese with English abstract)

Yang, Y. and Chui, T.F.M., 2017. Hydrodynamic and transport responses to land reclamation in different areas of semi-enclosed subtropical bay. Continental Shelf Research, 143: 54-66

Yang, Z. and Wang, T., 2013. Tidal residual eddies and their effect on water exchange in Puget Sound. Ocean Dynamics, 63(8): 995-1009

Ying, C., Li, R., Li, X. and Liu, Y., 2018. Anthropogenic influences on the tidal prism and water exchange in Yueqing Bay, Zhejiang, China. Journal of Coastal Research(85): 961-965

Yuan, Y., Jalón-Rojas, I. and Wang, X.H., 2019a. Impact of coastal infrastructure on ocean colour remote sensing: a case study in Jiaozhou Bay, China. Remote Sensing, 11(8): 946

Yuan, Y., Jalón - Rojas, I., Wang, X.H. and Song, D., 2019b. Design, construction, and application of a regional ocean database: A case study in Jiaozhou Bay, China. Limnology and Oceanography: Methods, 17(3): 210-222

Zarzuelo, C., Díez-Minguito, M., Ortega-Sánchez, M., López-Ruiz, A. and Losada, M.Á., 2015. Hydrodynamics response to planned human interventions in a highly altered embayment: The example of the Bay of Cádiz (Spain). Estuarine, Coastal and Shelf Science, 167: 75-85

Zhang, X., Fagherazzi, S., Leonardi, N. and Li, J., 2018. A positive feedback between sediment deposition and tidal prism may affect the morphodynamic evolution of tidal deltas. Journal of Geophysical Research: Earth Surface, 123(11): 2767-2783

Zhao, K., Qiao, L., Shi, J., He, S., Li, G. and Yin, P., 2015. Evolution of sedimentary dynamic environment in the western Jiaozhou Bay, Qingdao, China in the last 30 years. Estuarine, Coastal and Shelf Science, 163: 244-253

Zhao, L., Wei, H. and Zhao, J., 2002. Numerical study on water exchange in Jiaozhou Bay. Oceanologia et Limnologia Sinica, 1: 23-29 (in Chinese with English abstract)

Zhu, J., Weisberg, R.H., Zheng, L. and Han, S., 2015. On the flushing of Tampa Bay. Estuaries and Coasts, 38(1): 118-131

Zimmerman, J.T.F., 1976. Mixing and flushing of tidal embayments in the western Dutch Wadden Sea part I: Distribution of salinity and calculation of mixing time scales. Netherlands Journal of Sea Research, 10(2): 149-191 